\title{
Construção teórico-metodológica de uma pesquisa: uma análise do caminho
}

\section{percorrido}

\author{
Theoretical-methodological construction of a research: an analysis of the path traveled \\ Construcción teórico-metodológica de una investigación: un análisis del camino recorrido
}

Recebido: 14/12/2021 | Revisado: 19/12/2021 | Aceito: 24/12/2021 | Publicado: 27/12/2021

\author{
Ana Claudia da Silva Oliveira da Cruz \\ ORCID: https://orcid.org/0000-0002-5190-8559 \\ Universidade Federal do Amazonas, Brasil \\ E-mail: anacaio.ac@gmail.com \\ Adriana Francisca de Medeiros \\ ORCID: https://orcid.org/0000-0001-9290-0417 \\ Universidade Federal do Amazonas, Brasil \\ E-mail: afdemedeiros@gmail.com
}

\begin{abstract}
Resumo
O domínio das metodologias de pesquisas científicas, pode ser um dos maiores desafios no desenvolvimento do trabalho científico. Todavia o conhecimento dos métodos adequados para realização de uma pesquisa é de extrema importância, para que o projeto tenha relevância científica. O presente artigo é um recorte da pesquisa em andamento intitulada "O perfil de uma escola pública de Humaitá- Am: uma análise do desempenho do Saeb e a relação com as práticas pedagógicas", pesquisa proposta para a linha de pesquisa, perspectivas teórico-metodológicas para o ensino das ciências humanas do programa de Pós-Graduação em Ensino de Ciências e Humanidades (PPGECH) da Universidade Federal do Amazonas (UFAM), que proporcionará, analisar no contexto de uma escola pública com melhor desempenho no SAEB (2019), práticas pedagógicas que favoreçam a qualidade do ensino e aprendizagem. O referido recorte buscará descrever o percurso metodológico escolhido para a pesquisa, conceituando teoricamente e apontando a importância do mesmo para a pesquisa. O ajustamento teórico-metodológico apresentado tem como base ponderações no domínio da disciplina de Pesquisa em educação.
\end{abstract}

Palavras-chave: Metodologia; Pesquisa Científica; Abordagem Qualitativa.

\begin{abstract}
Mastering scientific research methodologies can be one of the biggest challenges in the development of scientific work. However, knowledge of the proper methods to carry out a research is extremely important for the project to have scientific relevance. This article is an excerpt from the ongoing research entitled "The profile of a public school in Humaitá-Am: an analysis of the Saeb's performance and the relationship with pedagogical practices", research proposed for the research line, theoretical-methodological perspectives for the teaching of human sciences of the Graduate Program in Teaching of Science and Humanities (PPGECH) of the Federal University of Amazonas (UFAM), which will provide, to analyze in the context of a public school with better performance in the SAEB (2019), practices that favor the quality of teaching and learning. This cut will seek to describe the methodological path chosen for the research, conceptualizing theoretically, pointing out its importance for the research. The theoreticalmethodological adjustment presented is based on considerations in the domain of the Education Research discipline.
\end{abstract}

Keywords: Methodology; Scientific research; Qualitative approach.

\section{Resumen}

Dominar las metodologías de investigación científica puede ser uno de los mayores desafíos en el desarrollo del trabajo científico. Sin embargo, el conocimiento de los métodos adecuados para realizar una investigación es de suma importancia para que el proyecto tenga relevancia científica. Este artículo es un extracto de la investigación en curso titulada "El perfil de una escuela pública en Humaitá-Am: un análisis del desempeño del Saeb y la relación con las prácticas pedagógicas", investigación propuesta para la línea de investigación, perspectivas teórico-metodológicas para la docencia. de Ciencias Humanas del Programa de Posgrado en Docencia en Ciencias y Humanidades (PPGECH) de la Universidad Federal del Amazonas (UFAM), que brindará, para analizar en el contexto de una escuela pública con mejor desempeño en el SAEB (2019), prácticas que favorezcan la calidad de la enseñanza y el aprendizaje. Este corte buscará describir el camino metodológico elegido para la investigación, conceptualizando teóricamente, señalando su importancia para la investigación. El ajuste teórico-metodológico presentado se basa en consideraciones en el dominio de la disciplina Investigación en Educación.

Palabras clave: Metodología; Investigación científica; Enfoque cualitativo. 


\section{Introdução}

$\mathrm{O}$ ato de pesquisar implica em procurar resposta para determinada indagação, quando se trata de pesquisa científica essa procura precisa seguir alguns critérios importantes, pois a pesquisa científica, envolve procedimentos racionais e sistemáticos que se configuram na metodologia científica, o que pode conferir a pesquisa um grau maior de confiabilidade. "Entendemos por metodologia o caminho do pensamento e a prática exercida na abordagem da realidade" (Minayo, 2011, p.14), seguindo o pensamento da autora, pode-se dizer que a metodologia é a aplicação de métodos e técnicas na realização de uma pesquisa, ou seja, auxilia a descrição de todas as etapas pelas quais uma pesquisa passou, ademais, sendo uma forma de validar o conhecimento científico produzido. É ela que vai dizer como a pesquisa será realizada.

O método utilizado pela pesquisa deixa de fora crenças, ideologias e superstições que o pesquisador possa professar, quando se trata de pesquisa científica a ciência faz uso especificamente do método científico, como refere.

A ciência utiliza-se de um método que lhe é próprio, o método científico, elemento fundamental do processo do conhecimento realizado pela ciência para diferenciá-la não só do senso comum, mas também das demais modalidade de expressão da subjetividade humana, como a filosofia, a arte e a religião. (Severino, 2016, p. 106).

Ainda sobre o método, Severino (2016, p. 106), o conceitua como "um conjunto de procedimentos lógicos e de técnicas operacionais que permitem o acesso as relações causais constantes entre os fenômenos”, partindo desses princípios entende-se que para a realização de uma pesquisa científica é necessário o real envolvimento do pesquisador cabendo-lhe a responsabilidade por desenhar caminhos diretivos, a serem seguidos, assim como a divulgação dos resultados obtidos. Contribuindo com esse pensamento, Silva (2019, p. 65) refere que “ para alcançar o objetivo de uma pesquisa, há de se ter um ponto de partida sinalizando para um ponto de chegada".

É seguindo nessa direção que traçamos o objetivo deste artigo que é, apontar teoricamente, os conceitos básicos e a estrutura metodológica adotada, bem como apresentar uma breve construção histórica e as diferenças epistemológicas que perpassam os limites da pesquisa. Para tanto realizou-se uma pesquisa bibliográfica com alguns autores, mencionados no decorrer do referencial teórico, trazendo a luz do conhecimento, conceitos, definições e aplicabilidade da abordagem escolhida.

O referido artigo está constituído por dois tópicos onde serão traçados percurso metodológico da pesquisa e os resultados, além deste tópico introdutório e as considerações finais.

\section{Metodologia}

Discorrer sobre metodologia de pesquisa científica, exige um bom conhecimento teórico, com definições sólidas e sintáticas, pensando em trazer estas afirmações à produção, teremos como embasamento teórico para este tópico os seguintes autores: Bauman (2005), Chizzotti (2006), Gil (2002), Ludke \& André (1986) e Triviño (1987) entre outros.

Esta pesquisa terá uma abordagem qualitativa do tipo descritiva com caráter social, a escolha da metodologia é por entender que este é o caminho que melhor se encaixa ao objeto da pesquisa, além de englobar perfeitamente o objetivo e a problemática apresentada. Pesquisar utilizando essa abordagem significa procurar conhecer a realidade de um determinado ambiente partindo do seu contexto mais amplo, para então entender seus aspectos específicos.

O local escolhido para o desenvolvimento da pesquisa é no município de Humaitá - Amazonas, localizado ao sul do Amazonas, em uma escola localizada na zona urbana que oferece o Ensino Fundamental I, trabalharemos com as turmas de $5^{\circ}$ anos. O motivo que nos leva a investigar esse tema surge após uma análise dos resultados das avaliações do SAEB das escolas do referido município, onde foi possível observar que a maioria das escolas que oferecem o nível ensino fundamental I, que tem como fase avaliada os $5^{\circ}$ anos, obtiveram desempenho dentro da meta estabelecida pelo Índice de desenvolvimento da 
Educação Básica - IDEB, a partir de 2007. Esse contexto de avanço, foi mantido até o ano de 2013, no entanto, após essa data, algumas dessas escolas não conseguiram manter os índices que vinham obtendo, iniciando assim um cenário de declínio no desempenho apresentado.

Parte deste ponto a inquietação pela pesquisa, buscando o entendimento das possíveis causas dessa nova realidade, tomando como ponto de partida a realização de uma análise dos resultados apresentados pelas escolas públicas do município de Humaitá. Durante o estudo percebeu-se que havia uma escola que não seguia a mesma direção das demais, mantendo então um caminho de crescimento constante em seu desempenho, chegando a ter o melhor índice de crescimento em 2019.

Além dos dados de desempenho, também foi possível verificar que se tratava de uma escola localizada em uma área periférica da cidade, sendo esse o fator determinante para a decisão sobre o loco da pesquisa. Nesse contexto a proposta inicial é analisar a relação do desempenho nas avaliações padronizadas do SAEB, com as práticas adotadas pela escola na busca pela superação das metas estabelecidas pelo Ministério de Educação, bem como a melhoria da qualidade do ensino e aprendizagem da instituição pesquisada.

Para fins de conhecimento, apresentamos um quadro representativo sobre a participação da escola nas avaliações do Saeb, com resultados a partir do primeiro estrato censitário do IDEB ${ }^{1}$.

Quadro 1 - Resultados do Ideb da Escola

\begin{tabular}{|l|l|l|l|l|l|l|l|l|l|l|l|l|l|l|l|}
\hline \multicolumn{9}{|c|}{ Ideb Observado } & \multicolumn{5}{c|}{ Metas Projetadas } \\
\hline $\mathbf{2 0 0 5}$ & $\mathbf{2 0 0 7}$ & $\mathbf{2 0 0 9}$ & $\mathbf{2 0 1 1}$ & $\mathbf{2 0 1 3}$ & $\mathbf{2 0 1 5}$ & $\mathbf{2 2 0 1 7}$ & $\mathbf{2 0 1 9}$ & $\mathbf{2 0 0 7}$ & $\mathbf{2 0 0 9}$ & $\mathbf{2 0 1 1}$ & $\mathbf{2 0 1 3}$ & $\mathbf{2 0 1 5}$ & $\mathbf{2 0 1 7}$ & $\mathbf{2 0 1 9}$ & $\mathbf{2 0 2 1}$ \\
\hline 22.4 & 33.1 & $*$ & 44.4 & 44.8 & 55.3 & 44.9 & 55.6 & 22.5 & 33.0 & 33.5 & 33.8 & 44.1 & 44.4 & 44.7 & 55.0 \\
\hline
\end{tabular}

Fonte: Autores.

Em uma análise sistemática do quadro, percebe-se que a Escola Municipal Edmee Monteiro Brasil, manteve um crescimento constante nos índices de desempenho, superando as metas estabelecidas pelo Ministério da Educação. Na atual circunstância nacional, analisa-se que o sistema educacional em vigência, como fenômeno político-social, tem a escola como um espaço privilegiado de construção do sabe,r possibilitando a culminância de um processo radical de transformação. Nessa perspectiva, optamos por investigar o contexto sociocultural da escola pertencente a pesquisa, não há interesse aqui em atribuir a nenhuma causa isolada o possível fracasso ou sucesso no desempenho da escola nas avalições de larga escala, entende-se que tal fato depende de uma conjunção de fatores próprios e da situação de vida dos atores envolvidos nesse processo.

O desvelamento da vida diária escolar aponta para a complexidade das relações ensino-aprendizagem. Tais relações envolvem aspectos da política educacional, da formação de professores, das histórias individuais e profissionais, das relações da escola com os pais e destes com a escola, da relação face a face em sala de aula, da constituição de grupos em sala de aula, da constituição de normas e regras de funcionamento, entre outros (Souza, 2005, p. 52).

Nesse entendimento e compreendendo a necessidade de pesquisar a dinâmica da realidade escolar, a pesquisa será desenvolvida na escola supracitada, situada no município de Humaitá, que está localizado no sul do Amazonas e possui uma população estimada de 56 mil habitantes segundo o Instituto Brasileiro de Geografia e Estatística - IBGE (Dados 2020).

${ }^{1}$ Para certificação consultar: http://ideb.inep.gov.br/resultado/ 
A pesquisa que propomos tem um caráter social, onde pretende-se contribuir com o alcance de objetivos que possam proporcionar o desenvolvimento individual e coletivo dos sujeitos investigados, buscando entender a realidade socioeconômica, institucional e política em movimento dinâmico. Nesse sentido, apoia-se nas proposições de fluidez e dinamismo apontadas por.

Ora a medida que se avança os estudos da educação, mais evidente se torna seu caráter de fluidez dinâmico, de mudanças natural a todo ser vivo. E mais claramente se nota a necessidade de desenvolvimento de métodos de pesquisas que atentem para seu caráter dinâmico. Cada vez mais se entende o fenômeno educacional como situado dentro de um contexto social, por sua vez inserido em uma realidade histórica, que sofre toda uma série de determinações. (Ludke \& André, 1986, p.06).

Esta é uma pesquisa que analisará o contexto real do chão da escola para tanto, buscaremos desenvolver uma abordagem qualitativa. Como diz Trivino (1987) há dificuldades em estabelecer um conceito para esse tipo de abordagem, apontando principalmente para o que diz respeito à "abrangência do conceito, a especificidade de sua ação e aos limites deste campo de investigação" (Trivinos, 1987, p 120).

\section{Resultados e Discussão}

Ludke e André (1986), mencionam a crescente popularidade da abordagem qualitativa, mas destacam a existência de muitas dúvidas em relação sua caracterização, utilização, rigor científico e ainda o uso de termos que se refere aos tipos de pesquisa qualitativa, como se fossem equivalentes a própria abordagem.

Apesar da crescente popularidade dessas metodologias, ainda parecem existir muitas dúvidas sobre o que realmente caracteriza uma pesquisa qualitativa, quando é ou não adequado utiliza-la e como se coloca a questão do rigor científico nesse tipo de investigação. Outro aspecto que também parece gerar ainda muita confusão é o uso de termos como pesquisa qualitativa, etnográfica, naturalística, participante, estudo de caso e estudo de campo, muitas vezes empregado indevidamente como equivalentes. (Ludke \& André, 1986, p.12).

O universo de abrangência da abordagem qualitativa é amplo, sua preocupação está em trazer compreensões à forma como enxergamos a realidade e seus significados. Com relação ao universo de trabalho da abordagem qualitativa, Minayo, (2009, p.21), salienta que, "ela se ocupa, nas ciências sociais, com um nível de realidade que não pode e não deveria ser quantificado. Ou seja, ela trabalha com o universo dos significados, dos motivos, das aspirações, das crenças, dos valores e das atitudes".

Partindo da ideia inicial em traçar um perfil descritivos da escola investigada e apoiando-me em Gil (2002) faremos uso do tipo de pesquisa descritiva como instrumento para a composição de dados desta pesquisa que tem como "objetivo primordial a descrição das características de determinada população ou fenômeno ou, então, o estabelecimento de relação entre variáveis" (GIL, 2002, p.42).

Quando se propõe o mapeamento do ambiente de pesquisa, estabelecendo assim um perfil institucional, logo percebese a necessidade em descrever a característica da população que compõe essa instituição, os fenômenos ou experiências, para assim tornar visível suas percepções sobre a realidade cotidiana. Nesse sentido, concordamos com Triviños, (1987, p. 110), quando traz a proposição de que "o estudo descritivo pretende descrever com exatidão os fatos e fenômenos de determinada realidade".

Entende-se que, para realizar uma pesquisa qualitativa do tipo descritiva é necessário construir uma base teórica bem estruturada, pois a própria descrição em si exige do pesquisador um bom conhecimento sobre o assunto a ser descrito que 
no caso em questão trata-se de compreender a reação/motivação da comunidade escolar com a aplicação das avaliações externas nacionais, realizadas pelo SAEB, frente aos resultados obtidos durante o ano de 2019. Para tanto é necessário atentar para a capacidade de alcance de algumas pesquisas descritivas.

Algumas pesquisas descritivas vão além da simples identificação da existência de relações entre variáveis, e pretendem determinar a natureza dessa relação. Nesse caso, tem-se uma pesquisa descritiva que se aproxima da explicativa. Há, porém, pesquisas que embora definidas como descritivas com base em seus objetivos, acabam servindo mais para proporcionar uma nova visão do problema, o que as aproxima das pesquisas exploratórias. (Gil, 2002, p. 42).

É perceptível que existam limites que precisam ser respeitados na realização da pesquisa do tipo descritiva, para assim não comprometer a veracidade de seus resultados. E é pensando nesses limites que adotaremos a entrevista como instrumento para a produção de dados, a mesma será realizada com as professoras titulares das turmas de $1^{\circ}$ ao $5^{\circ}$ ano do ensino fundamental, a gestora e coordenadora pedagógica da escola pesquisada, associada a essa técnica estará a análise documental, onde serão analisados os documentos oficiais da escola, tais como Projeto Político Pedagógico - PPP e os relatórios de desempenho divulgados nos sites oficiais do MEC. Minayo (2011, p.64) cita a entrevista como uma técnica de coleta de dados com uma comunicação verbal ampla e a mais utilizada no processo de trabalho de campo. "Entrevista, tomada no sentido amplo de comunicação verbal, e no sentido restrito de coleta de informações sobre determinado tema científico, é a estratégia mais usada no processo de trabalho de campo".

Ludke e André (1986), consideram a entrevista uma das principais técnicas de trabalho para o uso em quase todo tipo de pesquisa, no entanto chamam atenção para a necessidade do entrevistador conhecer os limites deste instrumento, bem como respeitar suas exigências, para assim aproveitar o poder dessa poderosa arma de comunicação.

Esta é, aliás, uma das principais técnicas de trabalho em quase todo s os tipos de pesquisa utilizados nas ciências sociais. Ela desempenha importante papel não apenas nas atividades científicas como em muitas outras atividades humanas. Estamos habituados e muitas vezes ficamos irritados como o seu uso e abuso pelos meios de comunicação de massa, especialmente pela televisão, que nos atinge de forma direta e onde podemos flagrar frequentemente a inabilidade de um entrevistador que antecipa e força a resposta do informante, através da própria pergunta quase não deixando margem de liberdade de resposta, a não ser a própria confirmação. [...] Pois essa poderosa arma de comunicação as vezes tão canhestramente empregada, pode ser de enorme utilidade para a pesquisa em educação. É preciso, para tanto, conhecer os seus limites e respeitar as suas exigências. (Ludke \& André, 1986, p. 38,39)

Conceituando de forma mais específica Minayo (2009, p. 64) define a técnica de entrevista como uma conversa que pode ser feita entre duas pessoas ou ainda entre um grupo de interlocutores, a autora destaca que a entrevista deve ter como objetivo a produção de dados relacionados a pesquisa. "É acima de tudo uma conversa a dois, ou entre vários interlocutores, [...] ela tem o objetivo de construir informações pertinentes para um objeto de pesquisa, e abordagem pelo entrevistador, de temas igualmente pertinentes com vista a este objetivo".

Ao fazer uso da entrevista como técnica na coleta de dados o investigador estabelece uma relação de interação com o informante, este cenário torna-se favorável para que as informações sejam as mais fiéis possíveis. Nesse sentido é importantíssimo atentar para a relação estabelecida entre entrevistador e entrevistado, para as autoras.

De início, é importante atentar para o caráter de interação que permeia a entrevista. Mais do que outros instrumentos de pesquisa, que em geral estabelece uma relação hierárquica entre o pesquisador e o pesquisado, como na observação unidirecional, por exemplo, ou na aplicação de questionário ou de técnicas projetistas, na entrevista a relação que se cria é de interação, havendo uma atmosfera de influência recíproca entre quem pergunta e quem responde. Especialmente na entrevista não totalmente estruturadas, onde não há a imposição de uma ordem rígida de 
questões, o entrevistado discorre sobre o tema proposto com base nas informações que ele detém e que no fundo são a verdadeira razão da entrevista. (Ludke \& André, 1986, p. 39)

Pensando nesse ambiente de interação, o tipo de entrevista ponderada para esta pesquisa foi a entrevista semiestruturada, a opção por esse formato se deu, pelo entendimento de que a mesma apresenta em sua organização um certo direcionamento sobre o tema proposto, mas ao mesmo tempo deixa uma liberdade ao sujeito entrevistado de expressar sua visão de realidade de forma livre e democrática.

Minayo, (2009, p. 64) classifica a entrevista semiestruturada de acordo com sua organização como a "que combina perguntas fechadas e abertas, em que o entrevistado tem a possibilidade de discorrer sobre o tema em questão sem se prender a indagações formuladas". Discorrendo sobre os aspectos gerais da entrevista semiestruturada optou-se pela descrição de.

[...] em geral, aquela que parte de certos questionamentos básicos, apoiados em teorias e hipóteses, que interessam a pesquisa, e que, em seguida, oferecem amplo campo de interrogativas, frutos de novas hipóteses que vão surgindo à medida que se recebem as respostas do informante. Desta maneira o informante, seguindo espontaneamente a linha de seu pensamento e de suas experiências dentro do foco principal colocado pelo investigador, começa a participar na elaboração do conteúdo da pesquisa. (Triviños, 1987, p.146)

Partindo do princípio de que a entrevista será realizada com um grupo de sujeitos, entende-se que há necessidade de uma organização prévia para realização da mesma, pensando neste contexto busca-se suporte teórico para a estruturação das etapas a serem desenvolvidas na coleta de informações com o aporte do referido instrumento, nesse caso o embasamento será em Triviños, (1987) onde o mesmo estabelece algumas etapas na coleta de informações com o aporte do referido instrumento.

[...] primeiro, entrevistas individuais com pessoas dos diferentes setores envolvidos, logo se avança com grupos representativos de sujeitos de cada setor, finalmente, numa entrevista semiestruturada coletiva, formada por sujeitos dos diferentes grupos (professores, alunos, orientadores educacionais e diretores). Todas estas etapas da entrevistasse desenvolvem em processos de retroalimentação. Isto quer dizer, por exemplo, que aqueles pontos escuros, que não tem sido possível completar ou que aparecem como conflitos ou divergentes, nas entrevistas individuais e dos grupos, podem constituir em base para elaborar as questões iniciais da entrevista coletiva, que reúne todos os setores. (Triviños, 1987, p.146)

A associação da análise documental permitirá ao investigador perceber o ambiente que não será apontado nas falas dos entrevistados, não podemos esquecer por tratar de um instrumento que dependerá diretamente do pesquisador, há sempre a necessidade de cuidado em não deixar que suas crenças, valores ou história de vida venha interferir diretamente no seu modo de analisar o objeto da pesquisa.

A análise documental aqui será utilizada como técnica de auxílio, tem como principal característica remeter um tratamento analítico em documentos que ainda não tiveram nenhum tipo de análise, considerados como fontes primárias, permitindo a investigação de uma problemática de forma indireta, através de documentos produzidos pelo ser humano.

Cellard (2008), orienta que, antes de dar início a uma análise documental em si, após a seleção do documento a ser analisado, é imprescindível uma análise preliminar do documento, sendo necessário levar em consideração algumas etapas, que implicam em: levantar informações sobre o contexto em que o documento foi produzido, identidade do autor, autenticidade, confiabilidade e natureza do texto, conceito chave e lógica interna do texto.

Para o tratamento e análise dos dados coletados em nossa pesquisa, será adotado a técnica de análise de conteúdo, tendo em vista a necessidade de uma visão mais aprofundada sobre a realidade do ambiente onde estão inseridas as escolas, bem como a compreensão de seu cotidiano. Chizzotti, (2006) chama atenção para a aplicação da referida técnica nas pesquisas de abordagem qualitativas. 
Nessas análises qualitativas, o pesquisador procura penetrar nas ideias, mentalidades, valores e intenções do produtor da comunicação para compreender sua mensagem. São analisadas as palavras, as frases e temas que dão significação ao conjunto, para relacioná-las com a forma literária do texto, com o contexto sociocultural do produtor da mensagem: as intenções, as pressões, a conjuntura, a ideologia que condicionaram a produção da mensagem, em um esforço para articular o rigor objetivo quantitativo, com a riqueza compreensiva qualitativa. (Chizzotti, 2006, p.117)

É perceptível na fala do autor a preocupação com o rigor da técnica, no entanto ao mesmo tempo a necessidade pela descoberta, para tanto faz-se necessário estabelecer alvos a serem perseguidos, com relação aos objetivos do método análise de conteúdo, refere-se de modo geral.

De maneira geral, pode dizer-se que a sutileza dos métodos de análise de conteúdo corresponde aos seguintes objetivos: • a superação da incerteza: o que eu julgo ver na mensagem estará lá efetivamente contido, podendo esta, "visão" muito pessoal ser partilhada por outros? Por outras palavras, será a minha leitura válida e generalizável? • e o enriquecimento da leitura: se um olhar imediato, espontâneo, é já fecundo, não poderá uma leitura atenta aumentar a produtividade e a pertinência? Pela descoberta de conteúdos e de estruturas que confirmam (ou infirmam) o que se procura demonstrar a propósito das mensagens, ou pelo esclarecimento de elementos de significações suscetíveis de conduzir a uma descrição de mecanismos de que a priori não possuíamos a compreensão. (Bardin, 2011, p. 35).

O propósito aqui, não é apenas uma interpretação das informações, mas sim uma análise mais profunda do campo de pesquisa, para tanto nos apoiaremos em autores que consideram que uma boa análise não se esgota apenas na categorização, mas busca acrescentar novas discussões ao assunto pesquisado.

A categorização, por si mesma, não esgota a análise. É preciso que o pesquisador vá além, ultrapasse a mera descrição, buscando realmente acrescentar algo à discussão já existente sobre o assunto focalizado. Para isso ele terá que fazer um esforço de abstração, ultrapassando os dados, tentando estabelecer conexões e relações que possibilitem a proposição de novas explicações e interpretações. (Lüdke, 1986, p.49).

Dessa forma, busca-se estabelecer a relação entre as variáveis dentro do contexto escolar, bem como do referencial teórico abordado sobre o tema, para assim traçar um perfil mais fidedigno possível das instituições escolares participantes da pesquisa.

\section{Conclusão}

A finalização deste artigo não representa que se concluiu as possibilidades de entendimento sobre o assunto pesquisado. A intenção em apontar teoricamente os conceitos básicos e a estrutura metodológica adotada na pesquisa, foi proporcionada pela realização da atividade final da disciplina Pesquisa em Educação, do curso de especialização stricto senso do PPGECH, tendo assim a necessidade de conhecer e descrever as metodologias que norteiam as pesquisas realizadas em um contexto social.

Discorrer sobre metodologias não é algo que se possa classificar como simples, ainda que seja um assunto já abordado por diversos autores de renome, descrevemos aqui então, algumas das considerações inconclusivas. Diante dos conceitos e definições apresentados nos aportes bibliográficos entendeu-se que, a abordagem de pesquisa de melhor aplicabilidade para uma investigação de caráter social é a qualitativa, pois trata-se de uma abordagem que trabalha levando em considerações o universo dos significados (crença, valores, visão de mundo).

Para tornar transparente esse domínio tão complexo dos significados, a pesquisa descritiva executa bem esse papel, pois seu âmbito está em descrever a realidade buscando sempre a exatidão dos fatos, mesmo sabendo que a verdade absoluta é 
inatingível. A técnica de interpretação de dados que melhor expressa os resultados da pesquisa no contexto social é a análise de conteúdo, por tratar a informação de forma interna, ou seja, penetra nas ideias, valores e intenções do sujeito.

Os dados obtidos por meio das leituras teóricas e das discussões nas aulas da disciplina permitiram as análises sobre meus conhecimentos sobre metodologias do trabalho científico, senti-me desafiada a buscar mais conhecimento sobre o assunto, tendo em vista minha formação ser na área de matemática, compreendi a necessidade de dominar ao menos os conceitos básicos das abordagens de pesquisa, para assim realizar uma investigação que expresse confiabilidade científica.

Portanto fica bastante sólido no desenvolvimento deste artigo a enorme importância do uso das metodologias apropriadas ao tipo de pesquisa que se pretende desenvolver, mas observamos ainda que nenhuma metodologia tem o poder de ser fidedigna por si só, o sucesso da pesquisa depende também da experiência e criatividade do pesquisador. Diante deste contexto, nossa intenção ao realizar este trabalho é colaborar com outros pesquisadores para a melhor compreensão do referido assunto.

Por fim, com a expectativa de contribuir com o periódico sugerimos humildemente que os trabalhos futuros possam abordar assuntos relacionados a avaliações em larga escala na educação básica, entendemos que ainda é um tema pouco abordado cientificamente.

\section{Referências}

Bardin, L. (2011). Análise de conteúdo. Edições 70.

Bauman, Z.(2005). Identidade. Zahar.

Brasil. (2005). MEC. Portaria MEC nº 931, de 21 de março de 2005: Institui o Sistema de Avaliação da Educação Básica - SAEB. Diário Oficial da UniãoPublicado em: 22/03/2005. (55),Seção: 1, p.17. https://download.inep.gov.br/educacao_basica/prova_brasil_saeb/legislacao/Portaria931_NovoSaeb.pdf

Cellard, A. (2008). A análise documental. In: Poupart, J. et al. A pesquisa qualitativa: enfoques epistemológicos e metodológicos. Ed. Vozes. p. $295-316$.

Chizzotti, A. (2006). Pesquisa qualitativa em ciências humanas e sociais. Ed. Vozes.

Gil, A. C. et al. (2002). Como elaborar projeto de pesquisa. Atlas.

Humaitá. (2021). Projeto Político Pedagógico da Escola Municipal Edmee Monteiro Brasil. SME

Ibge. (2020). População estimada 2020. Instituto Brasileiro de geografia e Estatística. https://cidades.ibge.gov.br/brasil/am/humaita/panorama.

Inep.( 2021). Instituto Nacional de Estudos e Pesquisas Anísio Teixeira. http://ideb.inep.gov.br/resultado.

Ludke, M. \& André, M. E. D.A. (1986) Pesquisa em educação: abordagens qualitativas. EPU.

Minayo, M. C. de S; Deslandes, S. F \& Gomes, R. (2009). Pesquisa social: teoria, método e criatividade. Vozes.

Triviños, A. N. S. (1987). Introdução à pesquisa em ciências sociais: a pesquisa qualitativa em educação. Atlas.

Severino, A. J. (2016). Metodologia do trabalho científico. (24.ed.rev.) Cortez Editora, 2016.

Silva, V.L.R. (2019). Docentes universitários em início de profissão: movimentos e experiências no cotidiano da docência universitária. CRV.

Souza, M. P. R. (2005). Problemas na aprendizagem ou problema na escolarização? In Silva, D. \& Limbório, R. M. C. (org.). Valores, preconceito e práticas educativas. Casa do Psicólogo, pp 49-56 